\title{
Comparative Study of Water Absorption Behavior of Indian and Pakistani Tiles Using Conventional Neutron Radiography Technique
}

\author{
M. K. Alam ${ }^{a}$, M. N. Islam ${ }^{a}$ and M. A. Zaman ${ }^{b}$ * \\ anstitute of Nuclear Science and Technology, Atomic Energy Research Establishment, Dhaka 1000, Bangladesh \\ and ${ }^{b}$ Department of Physics, Jahangirnagar University, Savar, Dhaka, Bangladesh.
}

\begin{abstract}
Neutron radiography (NR) technique has been adopted to study water absorption behavior of single layer tiles made of India and Pakistani raw materials, obtained from Concord Real Estate \& Building Products, Shalna, Gazipur, Dhaka, Bangladesh. Measurements were made to study the water absorption behavior of the tiles at different immersion time within the range of 24 hours using conventional NR technique. A series of neutron radiographs of these tiles have been taken at dry and wet condition to observe the water absorption behavior. The optical density differences between the film background and at different reference positions of the radiographic images of the dry and wet samples were measured. In the work it was observed that the water absorption in tiles of Indian origin is less than the other ones. Thus the former one seems better to use for construction purpose.
\end{abstract}

Key words: Neutron radiogdraphy, Homogeneity, Water absorption behavior

\section{Introduction}

Neutron radiography is a powerful non-destructive imaging technique for the internal evaluation, such as voids/cavity, cracks, homogeneity etc. of materials or components. It involves attenuation of a neutron beam by an object to be radiographed and subsequently registration of the attenuation process (as an image) is done on film or video. A very well known technique of non-destructive examination for characterizing the internal structure of an object is the use of penetrating radiation, such as x-ray radiography and neutron radiography. These two radiographic processes are often complementary. X-rays are stopped by dense materials and pass through light ones and in many instances neutrons have reverse properties. Neutron will penetrate the body of a large metal to give a good image of an internal structure. But for $\mathrm{x}$-ray to record it, it would require long exposure, which would obliterate most of the details available by the radiography. These are the most important advantageous of the radiography method over other methods available for doing this experiment. Neutron radiography method has been used to detect internal defects/ water absorption behavior in different building industries; Jute reinforced polymer/ biopol composites (Islam et al. 2000, Alam et al. 2007, Alam et al. 2006). It is also used to investigate the quality of different rubber samples (Islam et al. 2000).

\footnotetext{
* Corresponding author: E-mail: akramuzzaman50@yahoo.com
}

Many ancient cultures have made useful and decorative items such as pottery, figurines, building tiles, and burial containers that become important parts of the archaeological record. The material aspects of clay and ceramic technology, the physical properties of clay and various constructions and firing methods can be investigated using archaeometric technique (Renfrew et al. 1996, Rice 1987) Ancient Technologies and Archaeological Materials (ATAM) researchers have employed standard techniques such as $\mathrm{x}$ ray radiography, $\mathrm{x}$-ray diffraction (XRD), scanning electron microscopy (SEM), and neutron activation analysis (NAA) to study structure and composition of the ceramic materials (Renfrew et al. 1996, Rice 1987). In this paper, we present very promising results on water absorption behavior in the single layer tiles made of raw materials from India and Pakistan at different immersion time by using neutron radiography technique. These results are obtained with the measurement of optical density at different reference positions of the radiographic images of the dry/ wet samples and of the film background using digital optical densitometer.

\section{Neutron radiography facility}

The neutron radiography facility installed at the Institute of Nuclear Science and Technology, Atomic Energy Research 
Establishment, Savar, Dhaka at 3 MW TRIGA MARK II research reactor of Bangladesh Atomic Energy Commission, is equipped to facilitate inspection of radioactive samples (mainly, fuel rods) as well as non-radioactive materials. The tangential beam port allows for selection of thermal neutron beam and is used for neutron radiography because the neutron beam coming out through this port contains less amount of gamma - radiation (Islam et al. 1995, Rahman et al. 1989) compared to other three beam ports. Moreover, a $15 \mathrm{~cm}$ long bismuth filter is used inside the port to cut existing gamma - rays, because gamma - rays produce unwanted fogginess in the radiography film. To control the beam of neutrons, a $120 \mathrm{~cm}$ long conically shaped cylindrical divergent collimator having inner and outer diameter of $5 \mathrm{~cm}$ and $10 \mathrm{~cm}$, respectively, has been installed inside the reactor biological shielding assembly. Barton (1967) has described the usefulness of a divergent collimator for neutron radiography. A beam stopper, having 4 wheels at the bottom capable of forward and backward movement on rail in front of the beam port has also been installed. The beam stopper is a wooden box, which contains neutron-shielding materials, like paraffin wax and boric acid inside. The NR facility includes a beam catcher having a hole in the middle of the front face. A lead block has been placed at the back of the hole for gamma shielding and the remaining part of the beam catcher has been filled with neutron shielding materials. In between the beam stopper and beam catcher there is a sample and NR camera/ cassette holder table. Finally, the NR facility has been housed to reduce neutron and gamma background by using special concrete containing cement, heavy sand (mixture of ilmenite, magnetite and ordinary sand) and stone chips. Details of the NR facility can be found elsewhere (Rahman et al. 1989, Islam et al. 1995).

\section{Materials and Methods}

\section{Collection, preparation, shape and size of the sample}

The tiles samples have been collected from the Concord Ready-Mix Company, Bangladesh. These are manufactured with the help of very experienced management team consisting of skilled engineers and architects and their raw materials have been collected from the respective country (India and Pakistan). The company has a fully automated Italian press machine, which manufactures monolayer (single layer) tiles. There are also four more semi-automatic machines for the manufacture of double layer tiles (with backing). For final preparation the tiles are polished in a 10- head liner-grinding machine. After collection, these samples were dried at daylight to remove the water until we get their constant weight and then it is used as a test sample. The dimensions of these samples are 6"x 3"x 1.5". All of the samples are of rectangular shape.

\section{Loading of the film and converter foil in the NR-cassette}

The loading of the $\mathrm{x}$-ray industrial film (Agfa Structurix $\mathrm{D} 4 \mathrm{pDW})$ into the NR cassette $(18 \mathrm{~cm} \mathrm{X} 24 \mathrm{~cm})$ is a simple procedure (Arnold 1969), which requires only a little practice to be carried out easily in the darkroom. The loading should be done near the cupboard where the film is stored. The "dry" table should only be used for this work to prevent any contact of developing liquids with the unexposed loading film. There are a number of steps to place the industrial x-ray film into the NR cassette to protect the film against daylight and lamplight. While using proper illumination only, a film still in the interleaving paper is carefully drawn out from the box. The film was placed in the cassette by holding it between thumb and finger. A thin Gd metal foil of thickness $25 \mu \mathrm{m}$ was placed in contact with the emulsion surface and at the back of the film. It is very convenient and easy to load it in the dark.

\section{Placing sample and the NR-cassette}

The sample is placed directly on the sample holder table in close contact with the radiography cassette and the cassette is placed on the cassette holder table. Both are placed in front of the neutron beam (beam diameter $30 \mathrm{~cm}$ ).

\section{Exposure}

Exposure means passing of neutron beam through a sample onto a special film (x-ray industrial film) in order to create a latent image of an object in the emulsion layers of that film. This discussion is confined to direct contact radiography (film in close contact with the Gd converter foil) of the film. The sample was irradiated for the optimum time, i.e., the time required to obtain good neutron radiograph of the sample. Exposure time differs for different samples, depending on the intensity of the neutron beam, density and thickness of the sample and neutron cross-section. The optimum exposure time of both the samples was determined through a series of experiments with different exposure time, while the reactor was operated at $250 \mathrm{~kW}$. In this experiment the optimum exposure time is 1 hour. 


\section{Radiographic images}

In the NR-Cassette gadolinium foil was used as neutron converter and Agfa structurix D4 $\mathrm{DW}$ industrial $\mathrm{x}$-ray film was used as detector. After placing the NR-cassette and the sample on their respective table, dry/ wet sample was irradiated at an optimum exposure time of 1 hour at $250 \mathrm{~kW}$ reactor power, separately. Here the immersion time was 4, 6 and 24

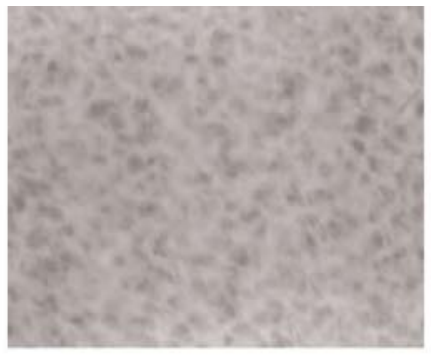

4 hours water absorption

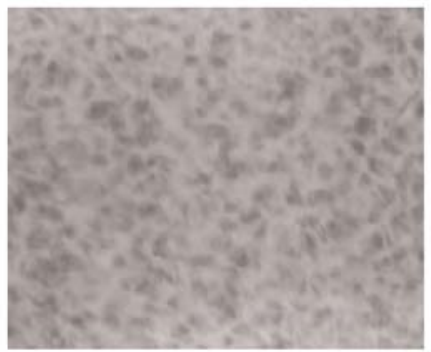

Dry
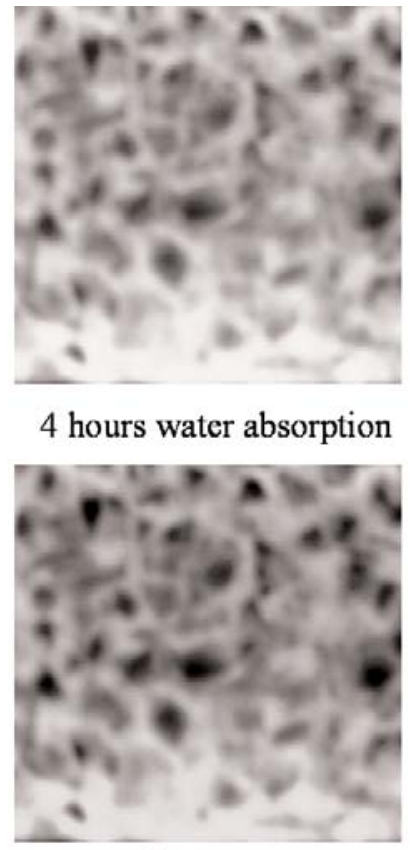

Dry hours. After irradiation the film was taken out from the NRcassette and chemically processed in a Kodak D-19 developer (for developing), in a flowing tap water (for washing) and in a Kodak unifix powder solution (for fixing) and then again finally washed in a flowing tap water in the dark room to obtain the radiographic images of the sample. After each immersion these processes have been applied to get the final neutron radiographs of the objects (Fig. 1).

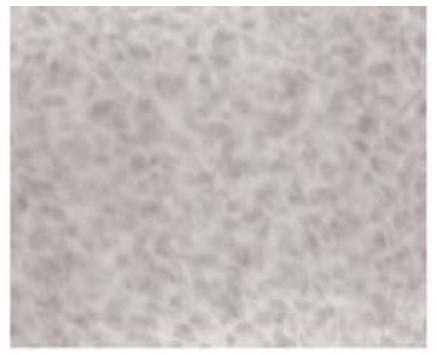

\section{6 hours water absorption}

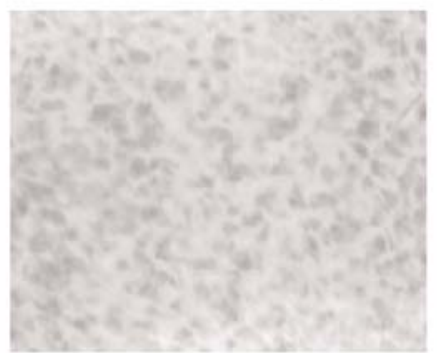

24 hours water absorption

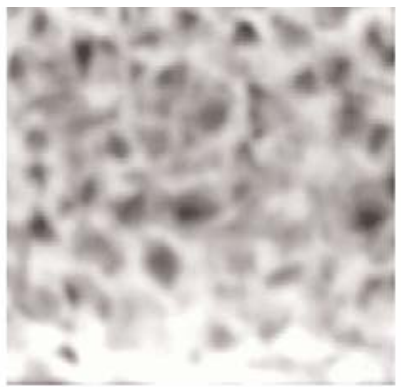

6 hours water absorption

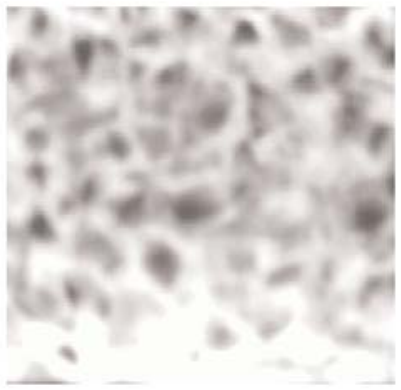

24 hours water absorption

Fig. 1: Radiographic images of (a) Indian tiles and (b) Pakistani tiles at dry and wet (at different immersion time) condition 


\section{Mathematical formulation}

When neutron beam hit an absorber, some of the neutrons are absorbed and scattered while the rest pass through the object. Attenuation of radiation in the object is the difference between the radiation intensity before reaching the object and after passing through this object. This is expressed in the following equation (Norris 1996):

$\mathrm{I}=\mathrm{I}_{0} \mathrm{e}^{-\mu \mathrm{x}}$

where, $\mathrm{e}=$ base of natural logarithms, $\mathrm{x}=$ thickness of the test object, $\mu=$ linear neutron attenuation coefficient, which depends on the atomic number and the density of the material.

In this work, the optical density of the sample image was measured by using the digital optical densitometer (Model 07-424, S-23285, Victoreen Inc. USA). Measuring average optical density of the radiographic film background, the optical densities at the center and at different positions of the radiographic image of the sample, one can comment about its water absorption behavior. With the help of equation (1) the mathematical expression (Harms et al. 1986) for the optical density at a point of the film, $\mathrm{D}$ is given by:

$\mathrm{D}=\ln \left(\mathrm{A}_{0} / \mathrm{A}\right)$

Here, $\quad \mathrm{A}_{0}=$ response of densitometer without the image and $\mathrm{A}=$ response of densitometer with the image. Using equation (2) the actual optical density, $\mathrm{D}_{1}$ at a point of the radiographic image can be written as

$\mathrm{D} 1=\mathrm{D}_{\mathrm{bk}}-\mathrm{D}_{\text {image }}$

Where $\mathrm{D}_{\mathrm{bk}}=$ optical density of the film background and $\mathrm{D}_{\text {image }}=$ optical density of the radiographic image of the dry/ wet sample. Hence using equation (3), average optical density difference, $\Delta \mathrm{D}$ of the radiographic image of the dry and wet sample (at different immersion time) can be defined as

$\Delta \mathrm{D}=$ average value of $\left(\mathrm{D}_{\mathrm{wt}}-\mathrm{D}_{\mathrm{dr}}\right)$

Here, $D_{w t}$ is the average optical density of reference positions of the radiographic image of the wet sample and $\mathrm{D}_{\mathrm{br}}$ is the average optical density of the same reference positions of the radiographic image of the dry sample.

\section{Results and Discussion}

Optical densities were measured at different positions of the film background and of the radiographic image of the wet/dry tiles samples using digital optical densitometer (Model 07-424, S-23285 Victorean Inc. made in USA). The actual optical density at different positions of the sample image was calculated using equation (3). Different optical density values were obtained at different point of the radiographic images of the samples because neutron attenuation is different at different point of the tiles samples. The variation of neutron attenuation through the samples create different optical density of the radiographic image. Fig. 2 shows the variation of the average optical density difference at different immersion time like 4, 6 and 24 hours of Indian (Fig. 2a) and Pakistani (Fig. 2b) tiles samples. During 24 hours immersion time absorption of water of the Pakistani tiles is higher than that of the Indian tiles. In that case, the observed average optical density values were $0.24 \pm 0.190$ and $0.30 \pm 0.030$ for the Indian and Pakistani tiles sample, respectively. During 6 hours immersion time we observed that the absorption of water for each sample was almost equal and the optical density values were $0.16 \pm 0.020$ and $0.16 \pm 0.037$ for India and Pakistani tiles, respectively. On the other hand i.e during 4 hours immersion time absorption of water for Indian and Pakistani tiles samples was almost same and observed average optical density values were $0.08 \pm 0.020$ and $0.06 \pm 0.035$, respectively. From the above points of view it was concluded that water absorption behavior of the Indian tiles was very poor with respect to Pakistani tiles. Figure 2 also shows that average optical density of each sample images increases sharply during the first 6 hours immersion time and from 6 to 24 hours immersion time their water absorption rate was very slow. It is worth mentioning here that the large optical density values indicate that the rate of water absorption is large. As a result increase of water absorption due to the sample increases the brittleness of that sample and little water absorption shows its reverse characteristics. Author also reported that within the area of interest of each samples the elemental distribution in the Indian tiles is homogeneous in contrast to the Pakistani tiles and no internal voids, cracks were found within the radiographic images of these two samples (Alam et al. 2007). From the above observations one may comments that, the application of Indian tiles for various purposes especially for bathroom and kitchen tiles, floor tiles, wall tiles, granite tiles etc. is better than that of the Pakistani tiles. 


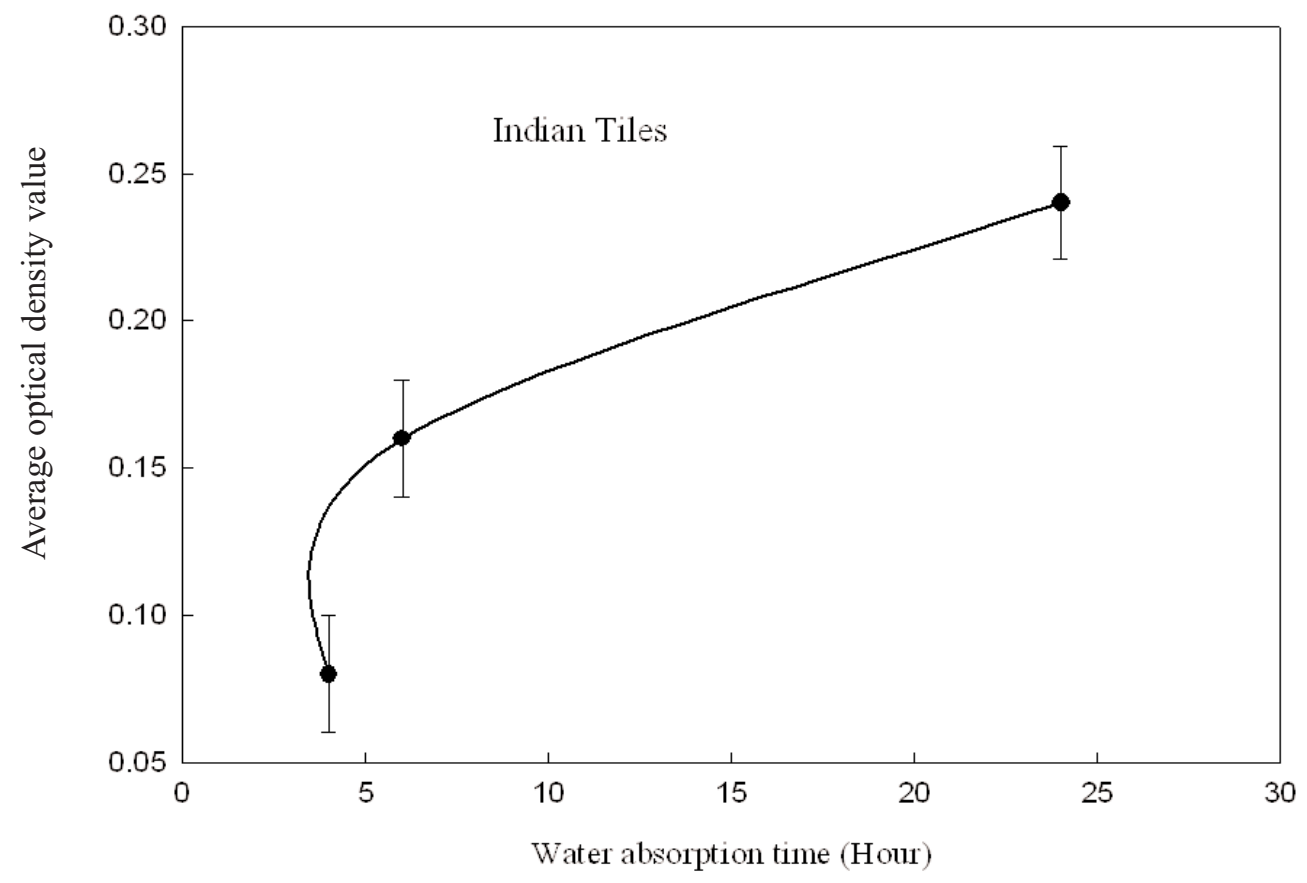

(a)

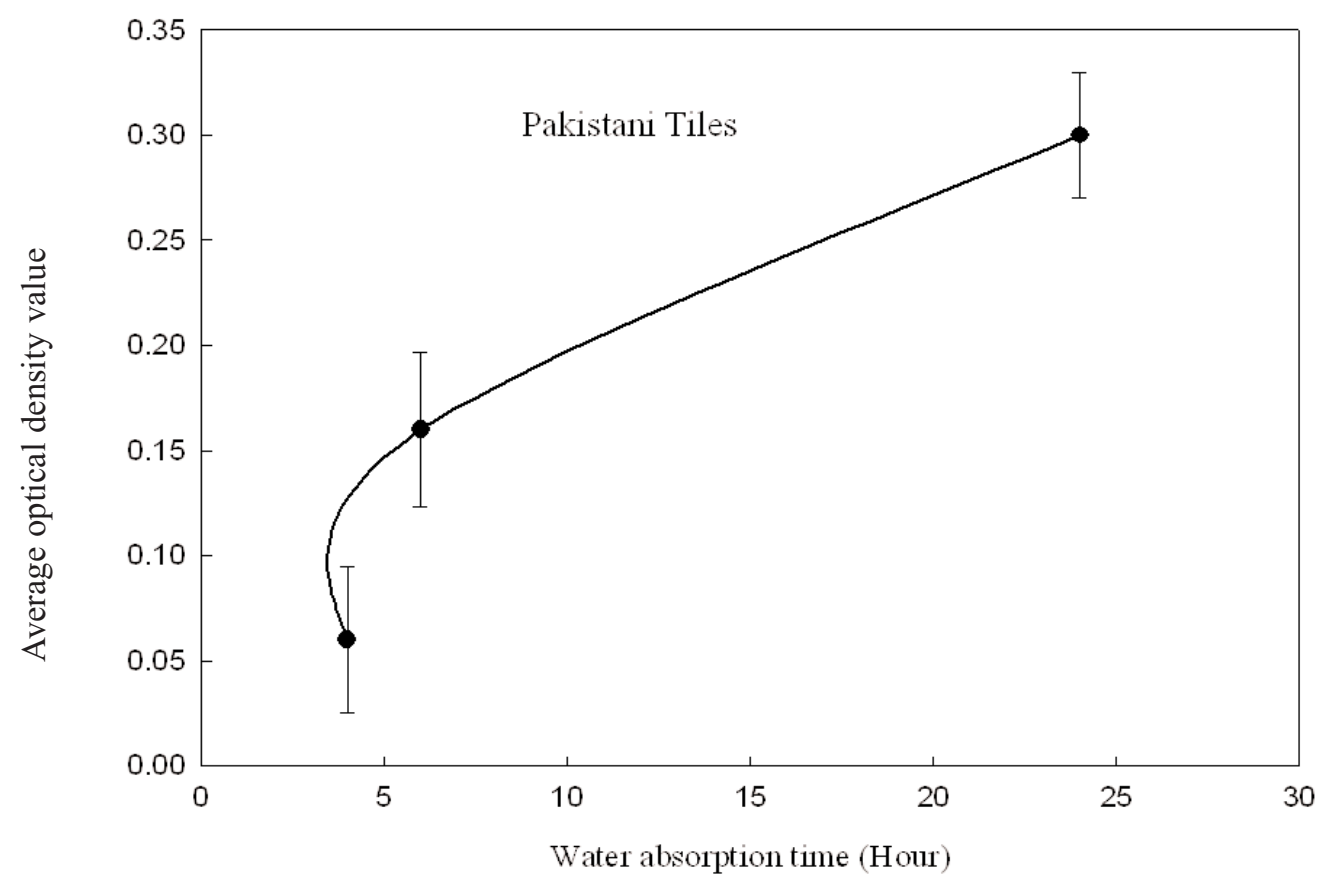

(b)

Fig. 2: Average value of optical density difference at different positions between the radiographic images of dry and wet (a) Indian and (b) Pakistani tiles 


\section{Conclusions}

Water absorption of Indian tiles is less than that of the Pakistani tiles. This technique is a very useful technique to observe the rate of water absorption behavior and the internal defects of different industrial products also.

\section{References}

Alam M. K. and Islam M. N. (2007). Study of internal defects in different tiles using film neutron radiography technique. Journal of Nuclear Science and Applications. 16 (1): 17.

Alam M. K. and Khan M. A. (2006). Study of water absorption and internal defects in jute reinforced biopol composite using digital neutron radiography technique. Journal of Bangladesh Academy of Sciences. 30: 29.

Alam M. K., Khan M. A. and Lehmann E. H. (2006). Comparative study of water absorption behavior in Biopol and jute reinforced biopol composite using neutron radiography technique. Journal of Reinforced Plastics \& Composite. 25: 1179.

Alam M. K., Khan M. A. Lehmann E. H. and Vontobel. P. (2007). Study of water uptake and internal defects of jute reinforced polymer composites using digital neutron radiography technique. Journal of Applied Polymer Science. 105 : 1958.

Arnold H. B. (1969). Methods for the study of sedimentary structures. A text book, Published by John Wiley and Sons and the author Arnold Bouma, New York, 1969, pp. 140.

Barton J. P. (1967). Materials evaluation, 45A: 259.
Harms A. A. and Wyman D. R. (1986) Mathematics and physics of neutron radiography, (D. Reidel Publishing Company, Holland), pp.22.

Islam M. N., Alam M. K., Zaman M. A., Ahsan M. H. and Molla N. I. (2000). Application of neutron radiography to building industries. Indian Journal of Pure \& Applied Phys. 38: 348.

Islam M. N., Rahman M. M., Islam S. M. A. and Zaman M. A. (2000). Neutron radiographic investigation of the quality of some rubber samples. Indian Journal of Pure and Applied Phys. 38: 675.

Islam M. N., Rahman M. M., Ahsan M. H., Mollah A. S., Ahsan M. M. and Zaman M. A. (1995). A study of neutron radiography parameters at the tangential beam port of the $3 \mathrm{MW}$ TRIGA research reactor of AERE, Savar. Jahangirnagar University Journal of Sciences. 19: 181

Norris P. M., Brenizer J. S., Raine D. A. and Bostain D. A. (1996). Measurements of water deposition in aerogel by neutron radiography. 5th World Conferenc eon neutron radiography, 17-20 June, 1996 Berlin, Germany.

Rahman M. A., Podder J. and Kamal I. (1989). Neutron radiography facility in Bangladesh research reactor. Proceedings of 3rd World Conference on neutron radiography, NR 3, May 14-18, 1989, Osaka, Japan.

Renfrew C. and Bahn P. (1996). Archaeology: Theories, Methods, and Practice. New York: Thames and Hudson.

Rice P. (1987). Pottery Analysis: A Sourcebook. Chicago: University of Chicago Press, New York.

Received: November 11, 2009;

Accepted : August 04, 2010 